\title{
Real-time on-farm N loss measurement
}

\author{
Samuel J. DENNIS* \\ Grounded, Hardys Road, Glenroy, RD1 Coalgate 7673, Canterbury, New Zealand
}

*Corresponding author: samuel@grounded.co.nz

\begin{abstract}
Empirical measurements of nutrient-leaching losses on farms are required in order to allow validation of models used to assess nutrient losses from New Zealand farmland. However such on-farm measurements have, to date, been generally impractical.

A new in-field leaching loss measurement system has been developed, based on well-established research methodologies. This system combines large strip lysimeters (10-20 m long) with largely automated, realtime leachate monitoring, which allows measurements to be taken over much larger areas for greatly reduced costs compared with other systems currently on the market.

A spatial computer modelling simulation showed that one such lysimeter can generate results of equivalent accuracy to an array of 12 fluxmeters, three lysimeters are equivalent to an array of 64 suction cups, and a larger number of lysimeters can be used to obtain more accurate results.

Nutrient loss is measured using off-site chemical analysis of flow-proportional subsamples of drainage water. In addition, electrical conductivity (EC) of the drainage water is measured continuously and correlated with past chemical analyses to provide real-time estimates of nutrient loss. Real-time EC measurements were strongly correlated with Total $\mathrm{N}$ concentration determined off site $\left(\mathrm{R}^{2}=0.89\right)$, which suggests that EC can be used as a proxy for Total N. However, a sitespecific regression of $\mathrm{EC}$ and $\mathrm{N}$ should be used for any actual estimation of $\mathrm{N}$ from $\mathrm{EC}$.
\end{abstract}

Keywords: lysimeter, fluxmeter, nitrogen, nitrate, leaching

\section{Introduction}

Measurements of soil drainage and nutrient loss are critical in New Zealand, due to environmental regulations that require farmers to operate within strict environmental limits. Unfortunately, drainage collection and measurement has always been complex and expensive. Drainage is invisible as it occurs below the soil surface. It is also variable, due to uneven water distribution (e.g. irrigation, microtopography) and uneven nutrient inputs (e.g. animal urine and faeces) (Moir et al. 2011). It is usually not possible to capture drainage from an entire paddock so drainage and nutrient loss must be sampled from small areas and then used to estimate loss from the paddock/plot. The variability of leaching means very large numbers of drainage measurement devices (lysimeters or ceramic cup samplers) must be used to obtain a reliable, accurate measurement (Lilburne et al. 2012). In-field measurements are expensive so an alternative approach is to measure leaching under controlled, experimental conditions, to determine the relationship between different variables (e.g. water inputs, fertiliser, crop type) and nutrient loss. These data are then used to create computer simulation models that estimate the expected nutrient loss in a wide variety of situations. Such models are very useful, particularly for "what-if" questions such as exploring the potential for nutrient loss under different scenarios and informing management decisions. However, models can never account for everything that may affect nutrient loss, because reality is far more complicated than any model can ever be. They must be calibrated and validated against in-field measurements in order to give meaningful results.

The expense of in-field measurement means that little empirical data have been collected, particularly from remote locations. As a result, computer models are being used to estimate nutrient loss for a large proportion of New Zealand farmland in situations in which they have not been adequately validated. The Parliamentary Commissioner for the Environment has specifically called for more "field trials to be used in calibration or corroboration" of such models to allow accurate estimation of leaching loss from New Zealand farmland (Upton 2018).

The object of this work was to develop a system that could enable such trials, by collecting data of comparable accuracy to existing in-field leaching measurement systems, but for a substantially lower cost. This would allow research institutions to collect much larger quantities of data within their existing budgets, while also allowing commercial enterprises and even individual farmers to measure leaching loss accurately.

\section{Nutrient loss measurement methods}

Four primary leaching-loss measurement tools are used in New Zealand:

1. Intact column lysimeters (e.g. Cameron et al. 1992)

2. Repacked lysimeters (also known as fluxmeters, e.g. Norris et al. 2017)

3. Ceramic suction cups (soil solution samplers, e.g. Talbot 2016) 
4. Hydrologically isolated plots (e.g. Monaghan et al. 1989)

Intact column lysimeters (1) are ideal for controlled field-laboratory experimentation, and subsequent model development. However, they are expensive items, so the capital cost of installing them in large numbers for in-field leaching loss measurements is generally prohibitive.

Repacked lysimeters (2) and ceramic suction cups (3) are more cost-effective per unit than intact column lysimeters so can be installed in large arrays with lower capital cost. However, large arrays are expensive to install and also operate, as samples must be collected from the field from many devices, by hand, as required on an event basis. Furthermore, the need to either remove or modify such devices to allow cultivation introduces further management complexity and operating cost where cultivation is frequent.

Being small, both ceramic suction cups and small repacked lysimeters have the limitation that draining water may bypass the device completely, or be directed towards the device, causing inaccurate measurements. Ceramic suction cups have the added limitation that they do not directly measure leaching loss, they only take spot-samples of nutrient concentration. Drainage volume must be estimated or measured elsewhere before leaching can be calculated. Both systems are also difficult to install below the root zone in stony soils and, if installed too shallow, may fail to capture leaching loss correctly (Wang et al. 2012).

Repacked lysimeters (and, to a lesser extent, hydrologically isolated plots) have the further limitation that the soil inside the device has been artificially disturbed, and may behave differently to undisturbed soil, particularly due to the loss of preferential flow paths in the topsoil (Monaghan et al. 1989). These preferential flow paths do recover over time (Safadoust et al. 2011).

Hydrologically isolated plots (4) are simply plots containing perforated pipe drains, isolated from adjacent soil using buried impermeable barriers at the edge of the plot. These plots directly measure actual leaching loss from relatively large areas, with low labour requirements, and can even be automated to some extent. Unfortunately, they can only be used over poorly drained subsoils so are not applicable to the soils of greatest concern for leaching losses.

As a result, a leaching measurement system for use on freely drained soils has been developed as an alternative to fluxmeters and ceramic cups, with the following characteristics:

1. High accuracy, at least comparable to existing research sampling arrays.

2. Simple to use, accessible to all industry sectors (from farmers to universities).
3. Install below the root zone even in gravel and boulders.

4. Protect against data loss from leaks, flooding or sample loss.

5. Collect real-time data, for immediate feedback regarding farm-management effects on leaching.

This paper describes the development of the system rather than research data collected by the system. The new system was evaluated against two existing, published, New Zealand field leaching measurement systems and one hypothetical system using a computer modelling simulation.

\section{Materials and Methods}

After substantial design work, field installations of early prototypes of a suitable lysimeter began in May 2017. A first prototype of an electronic autosampler was developed in early 2018. A first prototype of the full system (lysimeter + autosampler) was installed in Canterbury in April 2018. Subsequently, seven production lysimeters were installed in 2019, in both Canterbury and Southland. The method described below represents the current GroundTruth lysimeter system.

\section{The GroundTruth lysimeter system}

A large, repacked, passive wick-strip lysimeter is equipped with an autosampler that measures drainage volume and estimates nutrient content in real time, subsamples drainage water, and sends real-time data to the end user.

The GroundTruth lysimeter is a very large repacked passive wick strip lysimeter ("fluxmeter"). It is functionally equivalent to the systems described by Gee et al. (2009) and Norris et al. (2017) and used successfully around the world for many years. However, it is approximately 100 times larger (depending on the configurations compared), and shaped as a transect to incorporate spatial variation in leaching loss (most such devices are circular).

The GroundTruth lysimeter is $10-20 \mathrm{~m}$ long, 30-40 $\mathrm{cm}$ wide, and 70-100 $\mathrm{cm}$ deep, with a surface area of 4-10 $\mathrm{m}^{2}$ (existing passive wick lysimeters are generally $0.03-0.05 \mathrm{~m}^{2}$ depending on the manufacturer). It has sidewalls extending from the base of the lysimeter to approximately $30-\mathrm{cm}$ below the surface of the soil, similar to the large strip lysimeters used by Chrystal (2017). The sidewalls and base are sealed, all water that enters the lysimeter is collected.

The lysimeter also incorporates a $50-\mathrm{cm}$ hanging passive wick, that contacts the lower boundary of the soil profile inside the lysimeter, and finishes $50 \mathrm{~cm}$ below the average level of that lower boundary (Gee et al. 2009, Norris et al. 2017). This wick draws water from the entire length of the lysimeter to help to ensure 


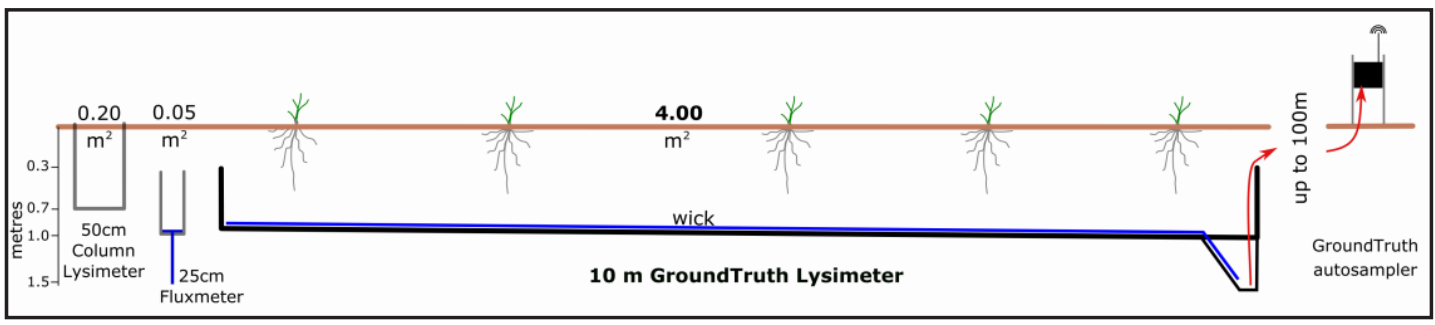

Figure 1 Below-ground construction of a 50-cm column lysimeter (Cameron et al. 1992), 25-cm fluxmeter (e.g. Decagon / METER G3), and GroundTruth lysimeter, comparing depth, sidewalls, wicks and capture areas.

that the soil moisture conditions inside the lysimeter are comparable to those outside (Gee et al. 2009).

Due to the large size, the perimeter:area ratio is also substantially lower $(5.2: 1$ for a $10 \mathrm{~m} \mathrm{x} 40 \mathrm{~cm}$ lysimeter, 20:1 for a $20-\mathrm{cm}$ diameter circular fluxmeter), to further reduce edge effects. The size and shape mean that drainage can be captured over a relatively large area, reducing the number of devices required to achieve appropriate sampling coverage.

The lysimeter is unaffected by either grazing or cultivation, as all components are below cultivation depth. As the lysimeter can be located as much as $100 \mathrm{~m}$ from the autosampler with no need for a slope between the lysimeter and autosampler, and even sample collection tubing is below cultivation depth, the paddock surface is unbroken in the vicinity of the lysimeter. This allows the lysimeter to be located well beyond headland areas and stock impacted zones by fence lines, and away from the autosampler itself, giving wide flexibility in lysimeter location without disrupting on-farm management. It can also be installed in soil with boulders up to $40-\mathrm{cm}$ diameter, while smaller lysimeters can only be installed in fine gravel or stoneless soils.

To minimise disturbance of the topsoil structure and maintain preferential flow paths, an implement was developed to remove the topsoil in intact blocks where the soil structure allows. Some disturbance still occurs even when the topsoil is removed in blocks, so like any cultivation event, some additional soil organic matter mineralisation and leaching is to be expected in the months following disturbance, however this should not compromise long-term leaching loss measurement. Carrick et al. (2017) installed a large repacked lysimeter and three large monolith lysimeters in November 2014. Between July 2015 and June 2016, the total nitrate-N leached from the repacked lysimeter fell within the range of loss from the monolith lysimeters (although the pattern of leaching differed slightly), meaning that by the winter following installation the repacked lysimeter could be used to correctly measure total annual leaching loss.

The GroundTruth autosampler is a briefcase-sized box, located above-ground in a position where it will not interfere with farm operations (e.g. beside a fenceline). The autosampler is solar powered and uses a long-range radio (LoRaWAN) to transmit data, allowing it to be installed on remote sites with no existing electricity or internet connections. The autosampler draws all drainage water from the lysimeter, measures drainage volume (by repeatedly filling and emptying a vessel of known volume), and measures drainage water electrical conductivity, in real-time, and sends to a server for further processing. It also collects a $1 \%$ subsample of all drainage and stores it for later collection $(100 \%$ of the water can be retained if desired).

Both drainage volume, and drainage nutrient content, can be measured in two independent ways.

- Volume is measured electronically, in real-time. Optionally, all drainage can be pumped after processing into a barrel or tank located on the soil surface near the autosampler, to allow a backup manual measurement of drainage volume.

- A $1 \%$ flow-proportional subsample of drainage is collected for laboratory analysis to determine nutrient concentration. This sample is stored in a belowground tank to minimise temperature fluctuations, and is retrieved on demand using a dedicated pump in the autosampler. The electrical conductivity (EC) of drainage water is also measured in real-time, and aligned to laboratory results to determine a sitespecific relationship between nutrients and EC.

An email alert is sent to a nominated person whenever a sample requires collection (according to customisable volume and/or time thresholds). When the email is received, the person visits the site, collects the water sample, and sends it to a laboratory for analysis. Realtime volume measurement and alerting allows samples to be promptly collected, minimising sample storage times, reducing the need for samples to be acidified as a preservative (and avoiding the health and safety risks of handling strong acids). However the system does allow samples to be acidified if needed for specific projects.

\section{Estimation of the number of lysimeters required}

The goal of the GroundTruth system was to be an 
alternative to fluxmeter and suction cup arrays, for in-field leaching measurement. This study involved a computer simulation comparing it with two existing, published, New Zealand field-leaching measurement systems along with one hypothetical field system.

1. Fluxmeter arrays, "Rootzone Reality" project (Foundation for Arable Research / Plant and Food Research). These arrays of 12 fluxmeters were designed to achieve an acceptable level of accuracy for on-farm measurement of leaching loss under arable farming (Norris et al. 2017).

2. SCALAR1 system, Ashley Dene (Lincoln University). This array of 64 ceramic cups $(5 \mathrm{~m}$ centres, $35 \times 35 \mathrm{~m}$ array within a $50 \times 50 \mathrm{~m}$ plot) was designed to measure leaching loss under grazed forage crops (Talbot 2016).

3. Hypothetical intensive system: 144 suction cups, $3 \mathrm{~m}$ spacings, 12 rows of 12 . This represents an extremely high intensity regularly spaced suction cup array.

This study did not attempt to define what an "acceptable" level of accuracy is. Rather, it was assumed that System 1 represented an acceptable level of accuracy for on-farm arable crop measurement, System 2 represented an acceptable level of accuracy for intensive research under grazing, and System 3 represented an ambitious level of accuracy. The aim of this computer simulation was to determine how many standard-length $(10 \mathrm{~m} \times 40 \mathrm{~cm})$ GroundTruth lysimeters, would be required to achieve equal or greater accuracy to each of the other systems.

There are physical differences between the GroundTruth lysimeter, the fluxmeter, and the suction cup, that may affect leaching loss accuracy (outlined previously). The depth of suction cups in the SCALAR1 system is also very shallow (only $35 \mathrm{~cm}$ ) compared to either the lysimeter or the fluxmeter system (both 1 $\mathrm{m})$. This study does not address these concerns, only comparing the sampling efficiency on an area basis.

A spatial model of urine patch distribution was built in R ( R Core Team 2015), informed by the model of Lilburne et al. (2012).

The SCALAR1 system involves use of a 50 x $50 \mathrm{~m}$ plot so all three systems were placed within the same sized plot for fair comparison. The SCALAR1 system was laid out as described above and in Talbot (2016). The Intensive system was laid out as described above. The fluxmeter array was laid out as three $7 \times 7 \mathrm{~m}$ squares, with $13.5 \mathrm{~m}$ between each square, approximating the actual field layout (Norris et al. 2017). GroundTruth lysimeters were spread around the plot in a regular arrangement.

The plot was represented as a large grid of $0.01 \mathrm{~m}^{2}$ pixels. Urine patches were each a circular arrangement of 34 pixels $\left(0.34 \mathrm{~m}^{2}\right)$. Any pixel receiving urine was assumed to leach $188.1 \mathrm{~kg} \mathrm{~N} /$ ha per year, and areas not receiving urine $22.8 \mathrm{~kg} \mathrm{~N} / \mathrm{ha}$ per year (Di \& Cameron 2007). GroundTruth lysimeters $(10 \mathrm{~m} \mathrm{x} 40 \mathrm{~cm})$ were represented as rectangles. Suction cups each sampled a single pixel. Each $20-\mathrm{cm}$ fluxmeter was represented by three pixels.

In this simulation, urine was randomly applied to the paddock, to cover approximately $20 \%$ of the paddock area (slightly varied between years), being an approximate annual cattle urine loading under grazing (e.g. Moir et al. 2011). Arrays of sampling devices were used to sample nutrient loss from this paddock area. This simulated the nutrient loss that would have been measured had that paddock contained each array of devices. The assumed total nutrient loss was calculated from the whole paddock (from the total area coverage of urine \& non-urine areas multiplied by the above annual leaching losses), and compared with the nutrient loss sampled by each sampling device array (calculated in the same fashion from only the parts of the paddock intercepted by the sampling devices). This process was repeated 1000 times, to simulate the leaching that would have been measured from each sampling array over 1000 years of random urinations.

The simulated sampled leaching measurement was considered "acceptable" if it was within 5,10 or $20 \%$ of the actual leaching value (Lilburne et al. 2012). The percentage of years in which an "acceptable" leaching measurement was received was determined for the three systems above, and for arrays of different numbers and sizes of GroundTruth lysimeters, to determine how many lysimeters were needed to achieve equivalent accuracy.

\section{Avoiding data loss}

Traditional lysimeters and fluxmeters are prone to leaks and/or flooding, which can cause uncertainty about data validity or result in complete loss of some data. For example, preliminary data from a 24-month trial using monolith lysimeters ( $0.8 \mathrm{~m}$ diameter, $1 \mathrm{~m}$ deep) was presented orally and summarised by Dennis et al. (2010), but only the last 12 months' worth of data was subsequently published in a peer-reviewed journal (Dennis et al. 2012) due, in part, to leaks in lysimeters identified in year 1 and repaired for year 2. Even the published data on leachate volumes from one soil type did not align with the water balance, suggesting some leaks may have remained. Flooding can also cause similar data loss (e.g. Chrystal 2017). The GroundTruth lysimeter reduces these risks by placing almost all working parts above ground (water is pumped up to the measurement system), and simplifying the belowground design to eliminate many potential sources of leaks. However, it is impossible to completely eliminate all risks, so the system also allows dual, redundant measurements of key parameters as outlined above. 
The nutrient concentration of any missing samples may be estimated from the EC. As drainage volume and $\mathrm{EC}$ are both measured electronically, in real-time and remotely, even if research staff are unable to access the site, nutrient loss can continue to be estimated from EC in real time, allowing research to continue.

To verify whether EC can be used to estimate nitrogen concentrations, all samples collected from four lysimeters located on the Canterbury Plains over the past two years were analysed for Total Nitrogen (N) using persulphate digestion and flow analysis, and Nitrate $\mathrm{N}$ using automated cadmium reduction and flow analysis, by Watercare Laboratory Services Ltd Invercargill. The $\mathrm{N}$ measurements were compared to EC using linear regression in R (R Core Team 2015).

\section{Results}

\section{Simulated sampling efficiency}

The difference between the simulated sampled $\mathrm{N}$ leaching loss, and the assumed total $\mathrm{N}$ leaching loss, over 1000 years of simulation is presented in Figure 2. Boxes represent lower and upper quartiles, and medians.
The percentage of years that the simulated values for each drainage sampling array are within 5,10 or $20 \%$ of the assumed total leaching loss are presented in Table 1. The number of GroundTruth lysimeters required to achieve equal or greater accuracy to each comparative system are indicated by special characters $\left({ }^{* \wedge} \sim\right)$.

The simulated sampled $\mathrm{N}$ leaching loss for the fluxmeter array was within $20 \%$ of the assumed total N leaching loss for $49 \%$ of the years simulated. A single GroundTruth lysimeter achieved the same result in 55\% of the years simulated. A single GroundTruth lysimeter appears to have a similar accuracy to an entire array of 12 fluxmeters.

For the SCALAR1 system (64 suction cups), the simulated $\mathrm{N}$ loss was within $20 \%$ of the assumed total $\mathrm{N}$ leaching value in $80 \%$ of the years, and within $10 \%$ in $46 \%$ of the years. An array of three GroundTruth lysimeters gave comparable accuracy.

For the 144 suction cup array, the simulated $\mathrm{N}$ loss was within $20 \%$ of the assumed total $\mathrm{N}$ leaching value in $95.6 \%$ of the years, which is comparable to the accuracy of an array of seven or eight GroundTruth lysimeters.

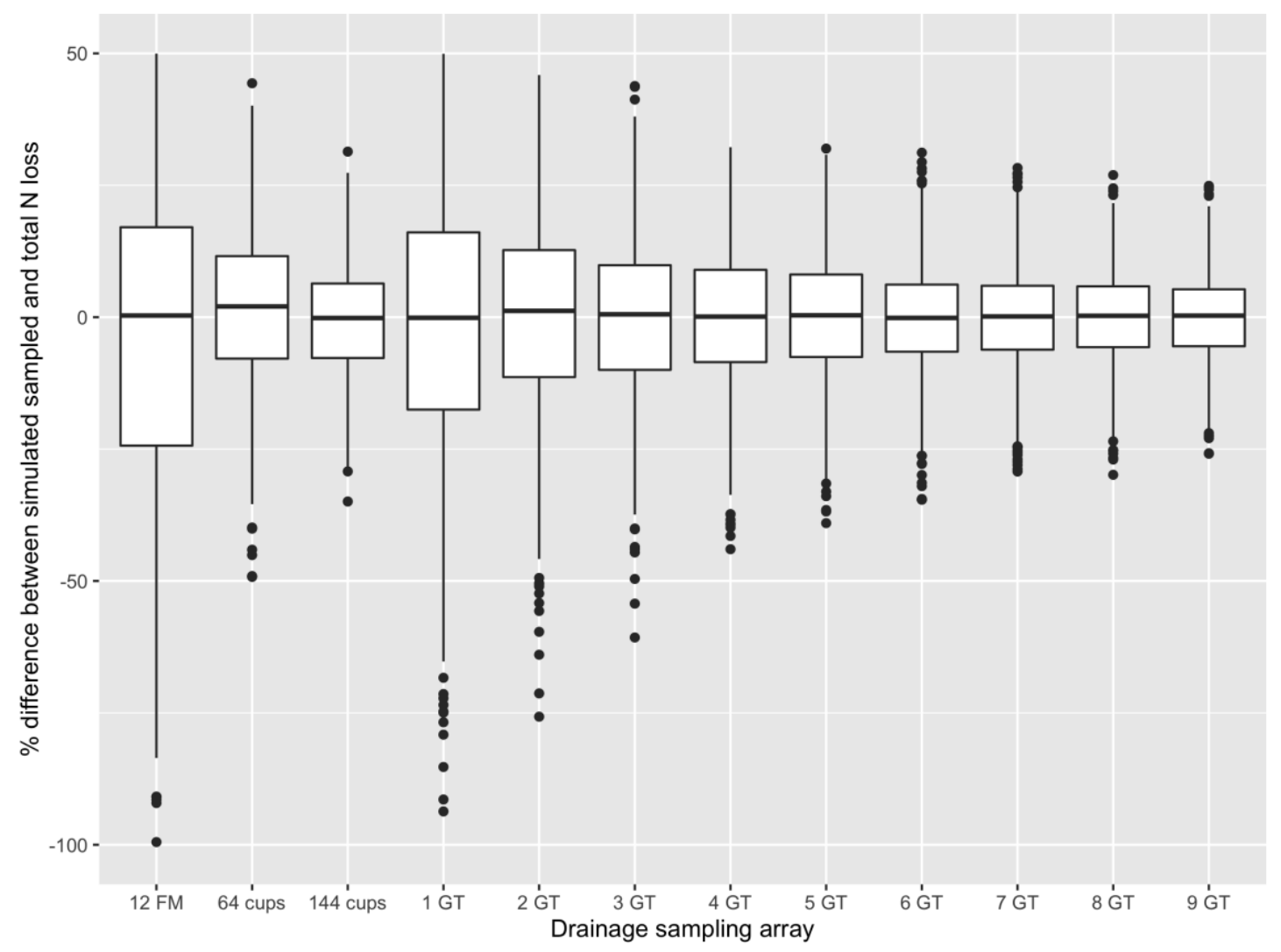

Figure 2 Difference between simulated Total $\mathrm{N}$ leaching and assumed total $\mathrm{N}$ leaching loss over 1000 years of simulated grazing. Sampling arrays are an array of 12 fluxmeters (FM), 64 or 144 suction cups, or 1-9 GroundTruth lysimeters (GT). 
Table 1 Percentage of years in which each simulated sampling array (fluxmeters, suction cups, or 1 to 9 GroundTruth lysimeters) measured within 5, 10 or $20 \%$ of the assumed total $\mathrm{N}$ leaching loss. Equivalent results shown as $\left({ }^{\star \wedge} \sim\right)$.

\begin{tabular}{lccc}
\hline & $\begin{array}{r}\text { Years (\%) measured within 5, 10 or 20\% } \\
\text { of the assumed total N leaching }\end{array}$ \\
\cline { 2 - 4 } Threshold & $\mathbf{5 \%}$ & $\mathbf{1 0 \%}$ & $\mathbf{2 0 \%}$ \\
\hline 12 fluxmeters * & 9 & 31 & 49 \\
64 suction cups ${ }^{\wedge}$ & 25 & 46 & 80 \\
144 suction cups $~$ & 42 & 67 & 96 \\
1 GT lysimeter & 17 & 31 & 55 \\
2 GT lysimeters & 19 & 40 & 73 \\
3 GT lysimeters & 27 & 50 & 83 \\
4 GT lysimeters & 30 & 56 & 88 \\
5 GT lysimeters & 34 & 61 & 92 \\
6 GT lysimeters & 38 & 65 & 94 \\
7 GT lysimeters & 38 & 70 & 95 \\
8 GT lysimeters $~$ & 43 & 73 & 97 \\
9 GT lysimeters & 45 & 76 & 98 \\
\hline
\end{tabular}

\section{Correlation between $\mathrm{EC}$ and $\mathrm{N}$ concentration}

Regressions of Total $\mathrm{N}$ and Nitrate $\mathrm{N}$ against EC are presented in Figures 3 and 4 respectively. A strong relationship was found to both parameters $\left(\mathrm{R}^{2}=0.76\right.$ \& 0.89).

\section{Discussion}

\section{Simulated sampling efficiency}

The object of this simulation study was not to determine the actual accuracy of any individual system, rather to determine the relative accuracy of the GroundTruth system when compared to other sampling arrays.

The situation simulated in this model was a simplification of reality. Only one source of withinpaddock variation was used (animal urine), and this was also a simplification as it ignored seasonal and edge effects. The actual within-paddock variation is likely to be lower under an arable crop, and higher under intensive forage grazing. It would be inappropriate to conclude that a fluxmeter array will always perform as poorly as simulated here, or that an intensive suction cup array will always perform as well as simulated here. These systems are designed for different situations, but are being compared in the same situation. This analysis simply shows how many GroundTruth lysimeters are needed to replicate the accuracy of these other systems, not precisely what that accuracy would be in any particular real-world situation.

Based on the simulation reported here, a single GroundTruth lysimeter has equivalent sampling efficiency to a 12-fluxmeter array. A single GroundTruth lysimeter is a valid option for exploratory studies or monitoring purposes. At least three lysimeters per treatment would still be required for statistical analysis.

Those three GroundTruth lysimeters would, however, give results of equivalent accuracy to the SCALAR1 array, a substantially more complex and costly system. Extremely high accuracy would be achievable by installing larger numbers of lysimeters.

The higher number of individual sampling units in fluxmeter and suction cup arrays is not necessarily an advantage for statistical analysis. Leaching loss from such systems can be highly variable, as some devices can measure exceptionally high or low loss due to very local effects (e.g. urine), resulting in datasets with nonnormal distributions that are difficult to analyse. The large GroundTruth lysimeters integrate both urine and non-urine areas within each device, so each lysimeter represents an "average" leaching loss. This makes the raw leaching data easier to understand intuitively, and easier to analyse statistically.

The GroundTruth lysimeter system appears capable of meeting or exceeding the accuracy of all in-field monitoring systems that are in current use in New Zealand, with fewer but larger sampling devices, making average leaching-loss measurements practical that have been impractical in most circumstances (Lilburne et al. 2012).

\section{Electrical conductivity}

Electrical conductivity will be affected by many solutes, and does not specifically relate to either Total $\mathrm{N}$ or Nitrate. However, because nitrogen is a major component of leaching, in practice the EC of soil water is correlated with both Total $\mathrm{N}$ and Nitrate concentration.

$\mathrm{R}^{2}$ values of $0.76 \& 0.89$ indicate that $\mathrm{EC}$ is a very strong predictor of both measures of $\mathrm{N}$. However it is a stronger predictor of Total $\mathrm{N}$, as this includes two major solutes that contribute to EC (ammonium and nitrate), while Nitrate $\mathrm{N}$ only includes one of these.

Different soil types and site management will alter the leaching of other solutes that also affect EC, so the relationship between $\mathrm{N}$ and $\mathrm{EC}$ differs between sites (data not shown). In practice, a site-specific regression of EC and $\mathrm{N}$ should be used for any actual estimation of $\mathrm{N}$ from EC. The overall correlations presented here are simply a demonstration of the basic principle, and should not be used to estimate the actual $\mathrm{N}$ concentration from any specific water sample.

The site-specific EC relationship can be used to estimate:

- Concentration of missing samples.

- Concentration of recent drainage, prior to analysis.

- Daily or hourly variation in concentration within a single sample (a physical sample may have been 


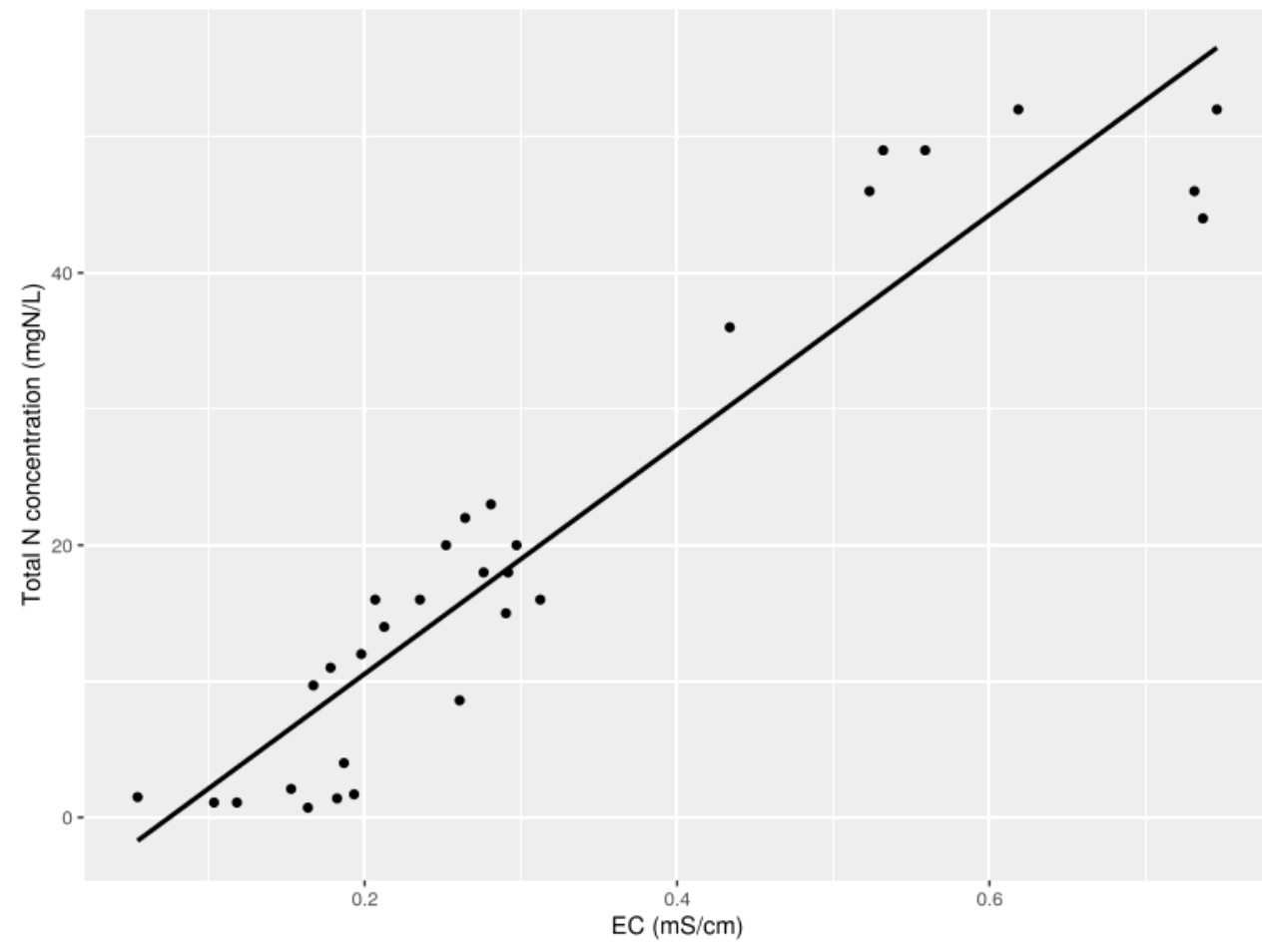

Figure 3 Regression of Total $N$ against $E C$. Total $N=-6.31+E C^{*} 84.28 . R^{2}=0.89$.

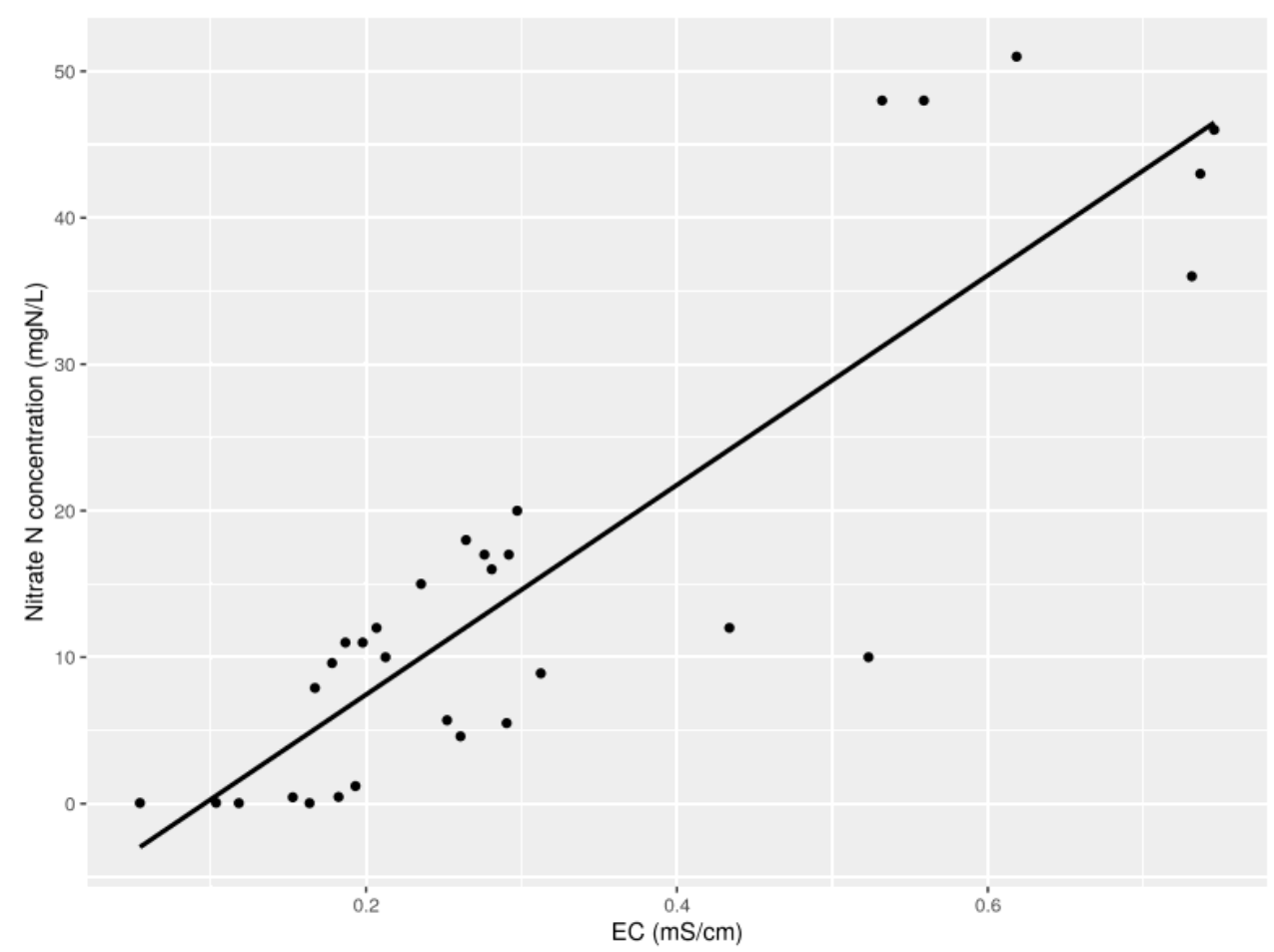

Figure 4 Regression of $\mathrm{NO}_{3}{ }^{-}-\mathrm{N}$ against $\mathrm{EC} . \mathrm{NO}_{3}{ }^{-}-\mathrm{N}=-6.87+E C^{*} 71.57 . \mathrm{R}^{2}=0.76$ 
collected over several weeks, EC records allow concentration changes over time to be examined at a higher resolution).

As EC is not specific to $\mathrm{N}$, it may also be possible to use it to estimate the concentration of other solutes.

\section{Practical implications}

Replacing many fluxmeters or suction cups with 1-4 GroundTruth lysimeters drastically reduces in-field labour. There is no need to modify the system before or after cultivation. Furthermore, there is no need to visit the site regularly to check whether drainage has occurred - drainage volume is measured electronically. The site only needs to be visited when drainage has actually occurred. Drainage collection only takes a few minutes, and can even be delegated to farm staff. The on-site research technician time is therefore only a fraction of the time required to operate a fluxmeter or suction cup array.

Sample retention times can also be minimised, as a sample can be collected as soon as it is available, and need not wait for the next scheduled visit.

In addition, the number of laboratory samples is greatly reduced, as only one sample is collected per device. Assuming 12 samples per device per year, there would be 144 samples from a 12-fluxmeter array, or only 12 from a single GroundTruth lysimeter. There would be 764 samples from an array of 64 suction cups, as opposed to 36 samples from an array of three lysimeters.

This means that two major components of the cost of research - labour and analysis costs - are both greatly reduced by this system.

The primary limitation of this system is that the lysimeter contains repacked soil, that may behave differently to the surrounding paddock. Soil disturbance has been minimised by developing an implement to remove and replace the topsoil in intact blocks. The remaining disturbance is a necessary compromise to allow construction of the lysimeter. This limitation is shared with other in-field measurement devices already used in New Zealand (Norris et al. 2017), and all alternative methods have their own limitations. There is no perfect leaching measurement system, all require some compromises.

Redundancy is provided against many unforeseen issues. During the COVID-19 lockdown of 2020, research staff lost access to one site where leaching is monitored using both GroundTruth lysimeters and a suction cup array. Suction cup data collection had to cease for approximately two months, but detailed drainage and EC records continued to be collected for three out of the four lysimeters on this site (one lysimeter suffered a breakdown that could not be repaired until lockdown ceased).

\section{Conclusions/Practical implications/Relevance}

An automated field lysimeter system was developed and field tested on a range of sites over two years.

The sampling efficiency of existing field leaching measurement arrays can be replicated using a small number of GroundTruth lysimeters, substantially reducing labour and analysis requirements to achieve comparable data quality. The system is simple enough for use by organisations that have previously not had access to accurate in-field leaching measurements.

Nutrient concentrations are measured through chemical analysis, with electrical conductivity provided as an additional backup measure. EC was found to be a very strong predictor of Total $\mathrm{N}\left(\mathrm{R}^{2}=0.89\right)$ and Nitrate $\mathrm{N}\left(\mathrm{R}^{2}=0.76\right)$, allowing the use of EC to estimate the concentration of missing samples, samples that have not yet been analysed, and to explore trends in nutrient loss at a finer timescale resolution than is possible with bulk samples.

The system has the potential to be a cost-effective yet accurate way to collect the large amounts of in-field leaching data necessary for model development and verification, and for many other purposes.

\section{ACKNOWLEDGEMENTS}

AGMARDT provided vital financial assistance towards the early development and later testing of the in-field lysimeter. Foundation for Agricualtural Research provided funding towards the installation of the first prototype system, and provided a site for a demonstration unit to be installed. The largest external funding providers have, however, been the early clients who have purchased systems to date, and who deserve the greatest acknowledgement and thanks, although they have not been named individually to preserve client confidentiality. Finally, Grounded is a family business, and this system would not exist without the practical support provided in many ways by the wider Dennis family.

\section{REFERENCES}

Cameron KC, Smith NP, McLay CDA, Fraser PM, McPherson RJ, Harrison DF, Hardbottle P. 1992. Lysimeters without edge flow: an improved design and sampling procedure. Soil Science Society of America Journal 56: 1625-1628. https://doi. org/10.2136/sssaj1992.03615995005600050048x

Carrick S, Rogers G, Cameron K, Malcolm B, Payne J. 2017. Testing large area lysimeter designs to measure leaching under multiple urine patches. New Zealand Journal of Agricultural Research 60: 205-215. https://doi.org/10.1080/00288233.2017.1291527

Chrystal J. 2017. Dairy wintering systems in southern New Zealand: quantification and modelling of nutrient transfers and losses from contrasting 
wintering systems. A thesis submitted in partial fulfilment of the requirements for the degree of Doctor of Philosophy in Soil Science at Massey University, Palmerston North, New Zealand.

Dennis SJ, Cameron KC, Di HJ, Moir JL, Richards KG. 2010. Dicyandiamide (DCD) reduces nitrate losses from Irish soils. Proceedings of the 19th World Congress of Soil Science. International Union of Soil Sciences, Brisbane, Australia. https://www.iuss. org/19th\%20WCSS/Symposium/pdf/1009.pdf

Dennis SJ, Cameron KC, Di HJ, Moir JL, Staples V, Sills P, Richards KG. 2012. Reducing nitrate losses from simulated grazing on grassland lysimeters in Ireland using a nitrification inhibitor (dicyandiamide). Biology \& Environment: Proceedings of the Royal Irish Academy 112. http://www.ria.ie/ getmedia/93fecc38-56a1-4d94-b6e8-f7c186acfa4e/ bae201124.pdf.aspx

Di HJ, Cameron KC. 2007. Nitrate leaching losses and pasture yields as affected by different rates of animal urine nitrogen returns and application of a nitrification inhibitor - a lysimeter study. Nutrient Cycling in Agroecosystems 79: 281-290. https://doi. org/10.1007/s10705-007-9115-5

Gee GW, Newman BD, Green SR, Meissner R, Rupp H, Zhang ZF, Keller JM, Waugh WJ, Van der Velde M, Salazar J. 2009. Passive wick fluxmeters: Design considerations and field applications. Water Resources Research 45: W04420. https://doi. org/10.1029/2008WR007088

Lilburne L, Carrick S, Webb T, Moir J. 2012. Computer-based evaluation of methods to sample nitrate leached from grazed pasture. Soil Use and Management 28: 19-26. https:// doi.org/10.1111/j.1475-2743.2011.00378.x

Moir JL, Cameron KC, Di HJ, Fertsak U. 2011. The spatial coverage of dairy cattle urine patches in an intensively grazed pasture system. The Journal of Agricultural Science 149: 473-485. https://doi. org/10.1017/0021859610001012

Monaghan RM, Cameron KC, McLay CDA. 1989. Leaching losses of nitrogen from sheep urine patches.
New Zealand Journal of Agricultural Research 32: 237-244. https://doi.org/10.1080/00288233.1989.10 423459

Norris M, Johnstone P, Green S, Clemens G, van den Dijssel C, Wright P, Clark G, Thomas S, Mathers D, Halliday A. 2017. Rootzone Reality - A network of fluxmeters measuring losses under cropping rotations. Summary of Year 1 and Year 2 results In: Currie LD, Hedley MJ Eds. Science and Policy: Nutrient Management Challenges for the next Generation. [Occasional Report No. 30]. Palmerston North, New Zealand: Fertilizer and Lime Research Centre, Massey University, 10 p. https://www. massey.ac.nz/ flrc/workshops/17/Manuscripts/ Paper_Norris_2017.pdf

$\mathrm{R}$ Core Team. 2015. R: A language and environment for statistical computing. R Foundation for Statistical Computing, Vienna, Austria. http://www.R-project. org.

Safadoust A, Mahboubi AA, Gharabaghi B, Mosaddeghi MR, Voroney P, Unc A, Sayyad Gh. 2011. Bacterial filtration rates in repacked and weathered soil columns. Geoderma 167-168: 204-213. https://doi. org/10.1016/j.geoderma.2011.08.014

Talbot W. 2016. Development of a new in situ system to measure nitrate leaching losses from winter grazed fodder beet. B. AgSci.(Hons) dissertation. Lincoln University, New Zealand. https://researcharchive. lincoln.ac.nz/handle/10182/7667

Upton S. 2018. Overseer and regulatory oversight: models, uncertainty and cleaning up our waterways. New Zealand Parliamentary Commissioner for the Environment. https://www.pce.parliament.nz/ publications/overseer-and-regulatory-oversightmodels-uncertainty-and-cleaning-up-our-waterways Wang Q, Cameron K, Buchan G, Zhao L, Zhang EH, Smith N, Carrick S. 2012. Comparison of lysimeters and porous ceramic cups for measuring nitrate leaching in different soil types. New Zealand Journal of Agricultural Research 55: 333-345. https:// doi.org /10.1080/00288233.2012.706224 